\title{
How do normal faults grow?
}

Atle Rotevatn $^{\mathrm{a}}$, Christopher A.-L. Jackson ${ }^{\mathrm{b}}$, Anette B.M. Tvedt ${ }^{\mathrm{c}}$, Rebecca E. Bell ${ }^{\mathrm{b}}$, Ingvild Blækkan ${ }^{\mathrm{a}}$

${ }^{a}$ Department of Earth Science, University of Bergen, PO Box 7800, 5020 Bergen, Norway

${ }^{b}$ Basins Research Group (BRG), Department of Earth Science \& Engineering, Imperial College, Prince Consort Road, London, SW7 2BP, UK

${ }^{c}$ Petrolia NOCO AS, Espehaugen 32, 5258 Blomsterdalen, Norway

*corresponding author: atle.rotevatn@uib.no (A. Rotevatn), phone: +47 48109959.

Keywords: normal fault; fault growth; isolated fault model; propagating fault model; coherent fault model; constant-length fault model; fault scaling

\begin{abstract}
Normal faults grow via synchronous increase in displacement and length ('propagating fault model', also known as the 'isolated fault model'), or by rapid length establishment and subsequent displacement accrual (constant-length fault model). We here use time-series displacement (D) and length (L) data from natural and experimental faults to elucidate growth styles and D-L trajectories throughout fault life, and to assess the applicability of the two fault models. We show that the growth of most faults is characterized by two stages, with the first defined by fault lengthening (20-30\% of fault lifespan) and the second by displacement accrual (70$80 \%$ of fault lifespan). Although broadly adhering to the constant-length model, fault growth throughout the lengthening stage, during which significant displacement (10$60 \%$ of the total end-of-life fault displacement) may also accumulate, is achieved through rapid tip propagation, relay breaching, and segment linkage, characteristics perhaps most intuitively thought to reflect growth in accordance with the propagating model. The subsequent growth stage is dominated by displacement accrual with limited lateral tip propagation, a phenomenon best described by the constant-length model. We also show that, despite being used primarily in support of the propagating
\end{abstract}


model, global displacement-length (D-L) datasets are equally compatible with the constant-length model.

(1)

8

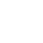

(1)
herein termed the 'propagating' and 'constant-length' fault models (e.g., Walsh et al., 2002; Walsh et al., 2003; Nicol et al., 2005; Jackson and Rotevatn 2013; Henstra et al., 2015; Fossen and Rotevatn 2016; Hemelsdaël and Ford 2016; Nicol et al., 2016; Tvedt et al., 2016; Childs et al., 2017; Jackson et al., 2017) (Fig. 1). The propagating model (also referred to as the 'isolated fault model'; see e.g. Jackson \& Rotevatn 2013; Childs et al., 2017) suggests fault growth occurs via a synchronous increase in fault length and displacement (e.g., Walsh and Watterson 1988; Dawers et al., 1993; Cartwright et al., 1995; Walsh et al., 2003), whereas the constant-length model suggests faults establish their near-final lengths early in their slip history, after which they grow mainly by displacement accrual (e.g., Walsh et al. 2003; Nicol et al., 2005; Jackson and Rotevatn 2013). To our knowledge, structural geology textbooks do not consider the constant-length model in their treatment of normal fault growth; instead, they focus entirely on propagation models (e.g., Davis et al., 2011; Fossen 2016). In the authors' opinion, it is therefore fair to say that the constant-length model is less well-known to the general structural community, outside of those specialising in fault growth. Because of this, we suggest there is a bias in favour of the propagating model in the earth science community overall, despite the mounting body of evidence to support the constant-length fault model (e.g., Nicol et al., 2010; Giba et al., 2012; Jackson et al., 2017; Rotevatn et al., 2018).

Understanding how normal faults grow is important for a range of earth science disciplines, with the styles and rate of tip propagation controlling, for example, the tectono-stratigraphic development of sedimentary basins (e.g., Gawthorpe and Leeder 2000; Ge et al., 2017; Henstra et al., 2017; Jackson et al., 2017), and the location, magnitude, and recurrence interval of potentially hazardous earthquakes (Walsh et al., 2003; Nicol et al., 2005; Soliva et al., 2008; Nicol et al., 2010). Despite mounting evidence in support of the constant-length model, the character of the initial lengthening stage remains unclear, including its duration (relative to the total lifespan of the fault) and its structural evolution (including growth pattern of faults), since few 
68 studies have been able to provide insight to the details of this early, relatively shortlived stage of fault growth (Schlagenhauf et al., 2008; Nixon et al., 2016).

Motivated by this, we here review the wealth of data published on fault length and displacement over the last 40 years and interpret new data from natural and experimental fault systems to investigate how a fault migrates through displacementlength (D-L) space as it grows. Using this data compilation we compare and contrast how these real and simulated faults behave in comparison to the often-used normal fault growth models described above. Using time-series fault displacement and length (D-L) data, we demonstrate that both models are applicable to the growth of normal faults, with each describing temporally distinct aspects of fault behaviours observed in nature and experiments. We conclude that most ancient normal faults, for which appropriate kinematic constraints are available, are characterized by: (i) an initial stage of length establishment (occurring over a time period of $20-30 \%$ of the total fault lifespan), characterized by rapid tip propagation, relay formation, -breaching and segment linkage, best described by the propagating model; this stage typically also involves accumulation of $10-60 \%$ of the final fault displacement; (ii) a subsequent stage of displacement accrual without significant further fault lengthening, best described by the constant-length model (occurring over a time period of $\sim 70-80 \%$ of the total fault lifespan). We also show that, despite being implicitly or explicitly used in support of the propagating fault model, in the scientific literature (e.g., Cartwright et al., 1995; Dawers and Anders 1995) and structural geology textbooks alike (e.g., Fossen 2016), global displacement-length (D-L) datasets (e.g., Marrett and Allmendinger 1991; Cowie and Scholz 1992b; Cowie and Scholz 1992a) are equally compatible with the constant-length fault model.

Using natural examples to document the structural and kinematic characteristics of the initial stage of fault propagation and lengthening may achieve significant future advances in our understanding of how normal faults grow. This stage is presently poorly documented and thus insufficiently understood due to: (i) a lack of reliable, preserved constraints from syn-kinematic growth strata; and/or (ii) the fact that any growth strata deposited during the initial, relatively short-lived state of fault growth may simply be too thin to detect using all but the highest-resolution geophysical methods (Jackson et al., 2017). 
102

103

104

105

106

107

108

109

110

111

112

113

114

115

116

117

118

119

120

121

122

123

124

125

126

127

128

129

130

131

132

133

134

135

The term 'propagating fault model' (Fig. 1A) describes the conventional model by which faults grow via a synchronous increase in their displacement and length (Fig. $1 C)$, i.e. the view that when faults accrue displacement they also lengthen by tip propagation and linkage via relay formation and breaching (e.g., Cartwright et al., 1995; Cowie et al., 2000; Kim and Sanderson 2005; Bergen and Shaw 2010). The propagating model is preferred, explicitly or implicitly, by numerous studies using observations from natural fault systems (e.g., Peacock and Sanderson 1991, 1994; Trudgill and Cartwright 1994; Wojtal 1996; Marchal et al., 1998; Morewood and Roberts 1999; Dawers and Underhill 2000; Gawthorpe and Leeder 2000; McGill et al., 2000; McLeod et al., 2000; Young et al., 2003; Soliva and Benedicto 2004; Commins et al., 2005; Hus et al., 2006; Bastesen and Rotevatn 2012), numerical modelling (e.g. Crider and Pollard 1998; Gupta et al., 1998; Cowie et al., 2000) and analogue models (e.g., McClay 1990; McClay and White 1995; Ackermann et al., 2001; Clifton and Schlische 2001; Mansfield and Cartwright 2001; Acocella et al., 2005; Bellahsen and Daniel 2005). What we herein refer to as 'the propagating model' is also sometimes referred to as the 'isolated model' (e.g., Jackson \& Rotevatn 2013; Childs et al. 2017), despite this term originally being used by Walsh et al. (2003) to describe the degree of kinematic and geometric coherency within a fault system, and not the presence or absence of tip propagation.

The propagating model is largely based on the observation that, when plotted in log-log space, fault displacement and length data appear strongly positively correlated across several orders of magnitude. This empirical relationship is described as $D=c L^{n}$ , where $D$ is maximum fault displacement, $L$ fault-trace length, $c$ a constant, and $n$ falls between 1 and 1.5 (e.g., Walsh and Watterson 1988; Marrett and Allmendinger 1990; Marrett and Allmendinger 1991; Cowie and Scholz 1992b; Marrett and Allmendinger 1992; Dawers et al., 1993; Schlische et al., 1996; Schultz et al., 2008; Torabi and Berg 2011; Rotevatn and Fossen 2012). Regardless of the exact value of $n$, the empirical relationship between $D$ and $L$ has historically been assumed to suggest that an increase in fault displacement $(D)$ is associated with a corresponding increase in fault length $(L)$ (Watterson 1986; Morley et al., 1990; Peacock and Sanderson 1991; Cowie and Scholz 1992b; Cowie and Scholz 1992a; Cartwright et al., 1995; Dawers and Anders 1995; Huggins et al., 1995; Peacock and Sanderson 1996; McLeod et al., 2000; Mansfield and Cartwright 2001; Rykkelid and Fossen 2002; 135

Kim and Sanderson 2005; Baudon and Cartwright 2008). In addition to fault 
136 displacement and length being positively correlated, support for the propagating fault 137 model includes: (i) the occurrence of breached relays and multiple displacement 138 minima along strike of normal faults (e.g., Gawthorpe and Leeder 2000); and (ii) 139 theoretical fracture mechanics, which predicts that for a given rock shear strength, 140 displacement and length must increase linearly (e.g., Cowie and Scholz 1992b). The 141 view that fault growth is achieved chiefly by lengthening and amalgamation of 142 individual segments means the propagating model is also commonly referred to as 143 'fault growth by segment linkage', or derivations thereof (e.g., Cartwright et al., 1995; 144 Cartwright et al., 1996; McGill et al., 2000; Jackson et al., 2002). It would be fair to 145 say that the propagating model has dominated the structural geology and tectonics 146 literature for decades, providing the basis for descriptions of normal fault growth in 147 textbooks (e.g., Davis et al., 2011; Fossen 2016).

148 Despite the fact it offers a relatively simple and thus appealing explanation of 149 global D-L scaling relationships, there are a number of challenges to the propagating 150 model. First, we know of no examples of presently active or extinct (i.e. ancient) 151 natural fault system, for which robust kinematic constraints have been presented (e.g. 152 growth strata or geomorphic evidence documenting tip propagation and fault 153 lengthening), that present compelling evidence faults are growing or grew in 154 accordance with the propagating fault model over geological timespans (i.e. $10^{4}-10^{6}$ 155 years; Jackson et al., 2017). Second, the propagating model appears incompatible with 156 the (generally much lower) displacement-length ratios of individual earthquakes (e.g., 157 Wells and Coppersmith 1994; Walsh et al., 2002; Nicol et al., 2005).

\section{The constant-length fault model}

160 The notion that major, through-going normal faults can 'rapidly' form was first 161 fully discussed in the seminal paper by Cowie (1998). A similar, rapid-establishment 162 theme is characteristic of the 'constant-length fault model' (Fig. 1B), which was 163 conceived and developed in a series of papers published from 2002 onwards. At least 164 partly motivated by the incompatibility between fault and earthquake D-L scaling properties, Walsh et al. (2002) presented what was initially termed an "alternative model" for the growth of normal faults. They argued that, contrary to the propagating

167 model, in which displacement and length increase in concert, “(...)fault lengths are 168 near constant from an early stage and growth is achieved mainly by increase in 169 cumulative displacement” (Fig. 2D). The term 'constant fault-length model' was 
170 subsequently coined by Nicol et al. (2005), to explicitly capture the fact that, for much

171 of their life, the studied faults experienced displacement accumulation rather than 172 lengthening (Walsh et al., 2002).

173 Most early work on the constant-length model was based on the analysis of 174 growth strata preserved next to relatively large (e.g. several kilometres in length, 175 several hundreds of metres of displacement), ancient faults imaged in 3D seismic 176 reflection data (Meyer et al., 2002; Walsh et al., 2002). Mounting support for the 177 constant-length fault model came from similar, seismic reflection-based studies (e.g., 178 Giba et al., 2012; Jackson and Rotevatn 2013; Tvedt et al., 2016; Jackson et al., 179 2017), as well as from numerical models (e.g., Finch and Gawthorpe 2017) and 180 analogue models (e.g., Schlagenhauf et al., 2008). Recent work has also used damage 181 zone geometry, and the scaling properties of exposed, relatively small-scale (i.e. up to 182 several metres of displacement) faults, to provide additional support for the constant183 length model (Nicol et al., 2016).

184 The constant-length model is attractive in that it offers a more dynamic view of D185 L scaling relationships (i.e. D-L scaling may change over time as a fault grows; see 186 Cladouhos and Marrett 1996; Rotevatn and Fossen 2012; Nicol et al., 2016), as well 187 as offering an explanation for the apparent mismatch between fault and earthquake188 rupture scaling relationships (Nicol et al., 2005). However, the constant-length model 189 initially appears at odds with the observation that relatively few ancient faults plot 190 below the regression trendline plotted in global D-L compilations; such faults should 191 at least theoretically occur if we assume some ancient faults became inactive early in 192 their development, shortly after the initial stage of lengthening, or, in the case of still193 active faults that are relatively immature.

194 Summarized, the constant-length model is built on the main premise that faults 195 propagate to their near-full lengths relatively rapidly (Walsh et al., 2002; Nicol et al., 196 2016), after which further lengthening is typically retarded due to mechanical fault 197 interactions between adjacent faults and an associated reduction of tip stresses (see 198 also Cowie 1998; Gupta and Scholz 2000). It remains unclear, however, how D and L 199 accumulation during fault growth is partitioned in time. Furthermore, existing work 200 on the constant-length model has focused predominantly structural characteristics and 201 timescales associated with the near-vertical D-L growth paths defining the 202 displacement accrual stage once the (near-)final fault length is established (e.g., 
203 Meyer et al., 2002; Walsh et al., 2002), but has shed limited light on initial fault 204 lengthening stage.

Motivated by the above review, and the fact the two models have co-existed for $\sim 15$ years, we find it timely to critically assess their applicability to describe the growth of normal faults. We therefore address the following key questions: i) how is fault lengthening partitioned in time?; ii) how is displacement accrual partitioned in time?; iii) what is the role of tip propagation and fault linkage throughout fault life?

211 Essentially, these questions all revolve around understanding fault behaviour in D-L 212 space through their lifespans. To address this, we study seismically imaged natural 213 normal faults, in addition to faults generated in analogue models, to extract D-L data 214 through time. D-L data for individual faults through time is key to understanding fault 215 growth, since the global D-L database really only shows a static view, where each 216 data point represents the final stage of what is essentially a fault's unknown journey through D-L space (Nicol et al., 2010; Rotevatn and Fossen 2012; Nicol et al., 2016).

218 With these data, and by addressing the above questions, we specifically aim to: (i) 219 elucidate the poorly-documented early lengthening stage of faults exhibiting a broadly 220 constant-length model-type behaviour; (ii) reassess the propagating and constant221 length models in an attempt to clarify their applicability to the growth of faults in 222 nature and experiments; and (iii) to suggest some key questions to be addressed in 223 future research.

\section{Fault behaviour in D-L space through time}

To reveal how faults grow in space and time, we present D-L data extracted at several points in the growth history of natural and experimentally reproduced faults

228 (Fig. 2). Data from natural faults are derived from throw backstripping of, and analysis of growth strata from, syn-sedimentary growth faults from the Egersund

230 Basin, offshore Norway (Tvedt et al., 2013; Tvedt et al., 2016) and the Santos Basin,

231 offshore Brazil (Tvedt 2016) (see cited papers and Jackson et al. 2017 for 232 backstripping method used and justification). Additional D-L data from natural faults 233 were extracted from Meyer et al. (2002), and experimental fault data from published 234 sandbox models (Schlagenhauf et al., 2008) and new plaster models (Blækkan 2016).

235 The plots of D-L evolution through time (Fig. 2) clearly show that only few 236 natural and experimental faults behave according to the predictions of the propagating 
model, i.e. exhibiting a corresponding increase in length as displacement is accrued (see inset $i$ in Fig. 2A). This observation, in concert with those from previous studies (e.g., Cartwright et al., 1996; McLeod et al., 2000; Commins et al., 2005; Hemelsdaël and Ford 2016), suggests that fault growth according to the propagating fault model does occur, but is an end-member behaviour rather than the norm.

Much more commonly, faults exhibit two-part growth trajectories in D-L space that can be split into an early, relatively low-gradient part, and a subsequent, relatively high-gradient part, separated by a moderately well-defined, fairly abrupt inflection point (see inset $i i$ in Fig. 2A). The high-gradient part is typical of fault behaviour according to the constant-length fault model, with the near-vertical growth trends in D-L space representing displacement accrual without significant fault lengthening (Meyer et al., 2002; Walsh et al., 2002). However, the initial, relatively low-gradient parts of the D-L graphs (Fig. 2A) exhibit great variability. For example, the D-L plots in Figure 2 show that the initial lengthening stage often involves not only lengthening, but may also involve (periods of) significant displacement accrual (up to 40-60\% of the total end-of-life displacement). The amount of displacement accrual varies, and the gradients in D-L space during this early stage of growth therefore also vary greatly, from relatively gentle, near-flat, constant-length-like gradients to steeper, propagating-like gradients (Fig. 2). These data thus document that, for faults that otherwise behave broadly in accordance with the constant-length model, a wide spread of D-L trajectories is seen during the initial lengthening stage. Such variability and complexity of the initial lengthening stage has, to our knowledge, not previously been demonstrated in other studies advocating the constant-length model (e.g., Walsh et al., 2002). This leads to the question "what style of growth (i.e. instantaneous length establishment vs. lengthening by tip propagation and linkage) characterizes the relatively low-gradient stage seen in the D-L paths, and is this 'lengthening' stage adequately captured and understood in the present models for normal fault growth?".

As discussed by Childs et al. (2017) and Jackson et al. (2017), seismic reflectionbased studies may show that faults establish their lengths within the first resolvable time increment but that, because this first resolvable time increment may be longer than the lengthening stage, the lengthening goes undetected. To investigate the lengthening stage further we therefore return to analogue models, in which this early stage of fault growth may be closely monitored and captured. In the following we discuss a plaster experiment (Figs. 3 and 4) of Blækkan (2016), first showing images 
271 of the experiment at relatively long (5-second) time-steps (Fig. 3), before showing the 272 early stages of the experiment at much shorter (0.5-second) time-steps (Fig. 4). We do 273 this to mimic having different temporal resolutions of data (i.e. low-resolution data at $2745 \mathrm{sec}$ time-steps vs. high-resolution data at $0.5 \mathrm{sec}$ time-steps), which may impact our 275 understanding of fault growth. For information about the experimental setup, see 276 Blækkan (2016).

277 Consider Figure 3, where we show a map-view image showing the evolution of a 278 large (relative to the scale of the experiment) normal fault (F1) at 5 second intervals 279 (timesteps T1-T4). Even after the first timestep (T2), F1 has grown across the width 280 of the model. The faults tips are pinned laterally at the experiment boundary, thus 281 emulating natural reasons for lateral fault tip pinning, such as the interaction with 282 other faults (e.g., Nicol et al., 2010). Further timesteps (T3 and T4) are characterised 283 by displacement accrual, accompanied by relay breaching. Based on viewing the 284 experiment at a relatively low temporal resolution (i.e. 5 sec timesteps), which we 285 compare to the limitations of the lowest resolvable time increment from growth strata 286 when analysing fault growth in the subsurface using reflection seismic and well data, 287 F1 thus appears to grow in accordance with the constant-length model.

288 By making the observational increments shorter (i.e. 0.5 secs) we can now 289 investigate the geometric and kinematic characteristics of the lengthening stage 290 between timesteps T1 and T2 (i.e. T1a-d; Fig. 4). A fault segment (termed main 291 segment S1; Fig. 4) that nucleates or at least breaches the surface in the western part 292 of the model during timestep T1a, propagates eastward and lengthens during 293 timesteps T1b and T1c. Fault lengthening during this stage is largely achieved by the 294 nucleation, propagation, and linkage of new, smaller segments ahead of the 295 propagating eastern tip of segment S1. In timestep T1c, a second segment (termed 296 main segment S2; Fig. 4) nucleates in the eastern part of the model, clearly separate 297 from the main S1 structure in the west. From timestep T1c to T1d, both tips of S2 298 propagate. Eastward propagation of S2 is arrested at the model boundary; the western 299 tip approaches the oncoming and now-rapidly eastward-propagating tip of S1. At 300 timestep T1d, the two main segments (S1 and S2) remain unlinked, but are 301 underlapping and approaching one another (sensu Peacock et al., 2017). The final, 0.5 302 second-long timestep between T1d and T2 sees hard-linkage of smaller S2 segments, 303 which were soft-linked during T1d, but hard-linked by T2. By T2, S1 and S2 have 304 overlapped and soft-linked, bounding a relay zone that is eventually breached by T3. 
The style of fault growth documented in time steps T1a through T1d (Fig. 4) is similar to that observed in some natural fault systems (e.g., Jackson et al., 2002;

307 Gawthorpe et al., 2003; Young et al., 2003), typified by tip-propagation and segment 308 linkage. These observations demonstrate that for a fault appearing to broadly behave 309 according to the constant-length fault model, tip propagation and segment linkage 310 govern the early, transient, relatively rapid lengthening stage of the fault (cf. Peacock 311 and Sanderson 1991; Cartwright et al., 1995; Walsh et al., 2003). This offers insights 312 into the structural characteristics of the early length-establishment stage, which has 313 rarely or never been fully captured in natural fault systems (see Hemelsdaël and Ford 314 2016; Nixon et al., 2016).

315 The example above also highlights that for a given fault, D-L ratios may change 316 abruptly as the fault lengthens by linkage of precursor segments. More specifically, in 317 our case an abrupt increase occurs between T1d $(\mathrm{D}-\mathrm{L}$ ratio $=$ c. 1.1) and T2 $(\mathrm{D}-\mathrm{L}$ ratio $318=$ c. 1.35) (Fig. 4 and Fig 3) (cf. Cowie 1998). As such, the kinematic significance of 319 D-L ratios recorded on active and inactive faults should be treated with care since 320 they: (i) may change with time on a single structure; and (ii) vary depending on the 321 length-scale considered (i.e. individual segment length immediately before, vs. full 322 fault length immediately after, linkage and establishment of the full fault length) 323 (Rotevatn and Fossen 2012; Nicol et al., 2016).

324 We now return to the D-L plots discussed initially in this section and shown in 325 Figure 2. The complex D-L paths observed in the lengthening stage may seem very 326 different to the well-known, sub-vertical D-L growth trends presented by Meyer et al. 327 (2002), which were used by Walsh et al. (2002) in support of the constant-length 328 model. However, the extracted D-L paths from Meyer et al. (2002) show that, 329 although sub-vertical growth trends are seen in the right hand part of the curves (Fig. 330 2D), there is an unresolved precursor stage that involves (i) not only lengthening, but 331 a variable amount of displacement accrual (10-60\% of total end-of-life displacement; 332 Fig. 2D) and (ii) overall lower-gradient (compared to the subsequent displacement 333 accrual stage), but somewhat variable trajectories through D-L space (Fig. 2D). This 334 important element of the early-stage growth of normal faults may previously have 335 been gone unnoticed, since D-L data from Walsh et al. (2002) and Meyer et al. (2002) 336 were presented only in log-log space. Plotting such data in log-log space is inherently 337 problematic, as it may unintentionally mask variability and statistical spread. 338 Interestingly, although the D-L paths presented in our study vary greatly, most of the 
339 D-L paths shown in Figure 5 fall within the cloud of the global D-L dataset when 340 plotted in log-log space. This highlights the danger of plotting data on logarithmic

341 scales, and demonstrates how radically different D-L trajectories of faults may 342 effectively 'hide' in log-log space. It also shows that one cannot infer 'typical' fault 343 growth trajectories in D-L space based on the often-cited correlation of fault 344 displacement and -length over several orders of magnitude. This is so because each 345 fault in the global data base is represented by a single, static, present-day D-L data 346 point, which contains no dynamic information whatsoever about the D-L trajectory 347 throughout the active life of each particular fault (cf. Cladouhos and Marrett 1996).

\section{Conclusions and future research challenges}

By using D-L data from a range of natural and experimentally reproduced faults, we have demonstrated that propagating (synchronous D-L growth) and constant-length (L-dominated followed by D-dominated growth) fault behaviours occur in nature. The critical point is that the different models appear to describe kinematic behaviours associated with specific times in the evolution of a fault; i.e. the propagating model, defined by tip propagation and segment linkage, characterises the initial, rapid and transient part of the lifespan of most faults, when its growth is dominated by lengthening, whereas the constant-length model characterises the latter part of the faults' evolution, when growth is dominated by displacement accrual (also see Nicol et al., 2016; Nixon et al., 2016; Finch and Gawthorpe 2017; Jackson et al., 2017; Rotevatn et al., 2018). Importantly, the constant-length model appears to be overall most applicable in the sense that a stage length of establishment is followed by a stage of displacement accrual without further fault lengthening. Our data uncover great variability in the fault D-L gradient paths during the initial lengthening stage; such variability has previously not been shown as previous studies have plotted D-L data in only log-log space.

We thus conclude that normal faults are generally characterized by hybrid growth behaviours whereby a rapid stage of fault propagation, linkage, and lengthening (Stage 1; lengthening stage) is followed by a stage of constant-length displacement

371 by a relatively abrupt inflection on the D-L curve (Fig. 6). Importantly, the 372 lengthening stage may also involve displacement accrual, and the gradient of the 
growth path during this stage may range from sub-vertical ('constant-length'-type gradient; trajectory 'a' in Fig. 6) to sub-horizontal ('propagating'-type gradient; trajectory 'e' in Fig. 6). The detailed growth behaviours seen in the first stage is most adequately captured by the propagating model, in that it involves tip propagation, segment linkage, overall fault lengthening and a variable amount of displacement accrual. The second stage is characterized by displacement accrual and limited fault lengthening. The D-L trajectory during this growth stage is typically sub-vertical, which is characteristic of growth according to the constant-length model (Meyer et al., 2002; Walsh et al., 2002). Fault behaviours demonstrated herein, whereby propagating and constant-length fault growth characterize successive stages of fault evolution, are identified in previous studies (Cowie 1998; Walsh et al., 2002; Jackson and Rotevatn 2013; Horne 2016; Nicol et al., 2016; Finch and Gawthorpe 2017; Rotevatn et al., 2018), although the lengthening stage remains to be more widely elucidated from natural examples.

The duration of each stage presented above remains uncertain. Normal faults analysed by Walsh et al. (2002) and Jackson et al. (2017) established their near-final lengths within $20-33 \%$ of their slip history; similarly, the majority of experimental faults in Schlagenhauf et al. (2008) grew to near-final lengths within c. $30 \%$ of their model durations. We therefore tentatively conclude that, irrespective of their final size, faults typically spend $20-30 \%$ of their lifespan in the lengthening stage (Stage 1), before accruing displacement for the remainder of their slip histories (Stage 2). Similar behaviours are seen in experimental strike-slip fault systems, where establishment of distributed faulting along the full final-length of the slip zone is nearinstant, whereas the formation and slip localization onto a fully through-going fault occurs at c. $30-35 \%$ of total fault duration (Hatem et al., 2017).

A critical research task to deepen our understanding of normal fault growth lies in undertaking more displacement backstripping studies of seismically imaged growth faults in order to investigate faults' D-L trajectories through time. Furthermore, new insight may be gained from reassessing the global D-L dataset to sort, examine, and analyse these data based on variables such as tectonic setting, strain rate, and host lithology; this may help us further elucidate setting-specific factors controlling fault behaviour.

A key future research challenge related to the growth of normal faults is to better document the initial lengthening stage described above. Insights may be gained by 
integrating high-resolution geophysical imaging techniques (e.g. reflection, sparker, pinger, boomer, and chirp profiling), which allow mapping of fault structure and associated growth strata, and borehole data, which may constrain the age of the growth strata and thus the timescale of fault development (e.g., Taylor et al., 2004; Nicol et al., 2005). Note that, in some active rifts, such as the Gulf of Corinth, Greece (e.g., Nixon et al., 2016; Bell et al., 2017; Gawthorpe et al., 2017), basin underfilling represents a drawback to the investigation of normal fault growth based on the analysis of growth strata (see discussion by Jackson et al. 2017).

Despite our tentative conclusion that the lengthening stage typically endures for $20-30 \%$ of fault lifespan, the duration remains uncertain, and more research is needed to fully understand what the notion of 'rapid' lengthening (e.g., Walsh et al., 2002) really entails. We speculate that the significant variability of D-L trajectories demonstrated for the lengthening stage (Stage 1) may translate to a similar variability in its duration. We further suggest that investigations into the (relative) duration of the lengthening stage should encompass the full spectrum of fault sizes in nature and experiments, to rigorously test whether duration is linked to fault size, despite the fact that we herein have tentatively concluded that it is not.

\section{Acknowledgements}

The geology department at the University of Otago, New Zealand, is thanked for hosting the first author for a research sabbatical, during which time this paper was written. We are grateful for well-considered, constructive, and elaborate comments from journal reviewers Nancye Dawers and Tom Manzocchi, which helped clarify and improve the final version of this paper. The authors would also like to thank colleagues who commented on a preprint version of this paper. We are particularly grateful to Michele Cooke for her insightful review of the preprint, and for enlightening Twitter discussions on fault growth.

\section{FIGURE TEXT CAPTIONS:}

Figure 1. Conceptual models for the development of surface-breaching, synsedimentary normal fault systems: (a) the propagating fault model (Walsh and Watterson 1988; Cartwright et al., 1995; Dawers and Anders 1995; Huggins et al., 
441 1995); and (b) the constant-length fault model (Childs et al., 1995; Walsh et al., 2002;

442 Walsh et al., 2003; Giba et al., 2012). The (i) plan-view, (ii) strike-projection and (iii)

443 displacement-length (D-L) plots are shown to illustrate the key geometrical and

444 evolutionary aspects of each model. The black arrows in (ii) show the fault level of

445 the map shown in (i). F1-3, faults 1-3; T1-3, time-steps 1-3. Note that, based on the

446 final fault length (i.e. T3 in i), shape (i.e. T3 in ii) and throw distribution (i.e. T3 in

447 iii), it is difficult to determine which growth model best describes its evolution. (c)

448 Schematic D-L plots through fault life according to the propagating fault model; time

449 steps correspond to those shown in (a). (c) Schematic D-L plots through fault life 450 according to the constant-length fault model; time steps correspond to those shown in 451 (b). (a) and (b) are from Jackson et al. (2017); (c) and (d) are modified from Nicol et 452 al. (2016).

454 Figure 2. Normalized maximum displacement (D) versus normalized fault length (L) 455 plots though fault life for a series of faults. (A) shows data from all faults studied 456 herein, whereas (B), (C), and (D) show selections of the data. The data includes 457 natural faults from Tvedt et al. (2013, 2016), Tvedt (2016), Meyer et al. (2002), faults 458 from plaster experiments by Blækkan (2016) and faults from sandbox experiments by 459 Schlagenhauf et al. (2008). Note that the data from Meyer et al. (2002) carries some 460 uncertainty as the data were manually extracted from the $\log -\log$ D-L plots in that 461 paper. Inset (i) shows D-L graphs for select faults that exhibit sympathetic D-L 462 growth, i.e. propagating fault growth. Inset (ii) shows D-L graphs from select faults 463 that show clearly separate low-gradient and high-gradient parts, separated by clear 464 inflection points. (B) shows data from natural faults extracted from Tvedt (2016) and 465 Tvedt et al. $(2013,2016)$. (C) shows data from faults produced in physical analogue 466 models from Schlagenhauf et al. (2008) and Blækkan (2016). (D) shows the data 467 extracted from Meyer et al. (2002); note however that we have added $(x, y)=(0,0)$ to 468 all the D-L curves, in order to illustrate that each of the vertical D-L graphs in Meyer 469 et al. (2002) have an additional unrecorded and unknown growth stage that is 470 illustrated by dashed lines. See text for full discussion.

472 Figure 3. Plaster experiment of normal fault evolution. Four timesteps, T1 through T4 473 at 5-second intervals, are shown. Timestep T1 is the experiment at the onset of 474 extension. To the right, displacement-length plots for the fault evolving in the 
experiment are shown for timesteps T2 (green), T3 (blue) and T4 (red). Note that the fault seen in T2 already at that stage has established itself across the extent of the model. See Figure 4 for four additional, shorter, 0.5-second timesteps immediately prior to timestep T2, which show the lengthening stage of the fault.

Figure 4. Plaster experiment of normal fault evolution; 4 timesteps are shown at 0.5 second intervals; T1a through T1d. These timesteps cover the 2 seconds leading up to timestep T2 in Figure 3; see Figure 3 caption for further explanation.

Figure 5. Global D-L dataset (grey data points) for faults plotted in log-log space (DScholz 1992a, and references therein; Dawers et al., 1993; Cartwright et al., 1995; Schlische et al., 1996; Schultz and Fossen 2002). The D-L paths shown in Figure 2 of this study are also shown. Note most of the different D-L paths from this study plot within the global dataset, despite that these growth paths show a wide range of behaviours (see text for full discussion). This demonstrates that the global correlation of D and L cannot be invoked to support 'propagating' fault growth, since 'constantlength' and hybrid growth patterns are all fully consistent with, and may hide within, the global D-L database as shown here.

Figure 6. Schematic illustration showing idealized D-L growth trajectories of the end member 'propagating' (green) and 'constant-length' (blue) fault models, as well as a series of hybrid fault growth trajectories (black). As shown in this paper, few faults follow the propagating or constant-length trajectories; most faults follow D-L growth paths that fall between the end-member models and are characterized by two stages. The first stage is characterized by rapid fault lengthening and a variable amount of

501 displacement accrual, and is best described by the propagating model since it is 502 associated with lengthening achieved by tip propagation, relay formation and breakdown, segment linkage and amalgamation to ultimately establish near-full fault

504 lengths at the end of Stage 1. The second stage (Stage 2), is best described as 505 'constant-length' fault behaviour, i.e. displacement accrual without significant tip 506 propagation or further fault lengthening. The fault growth trajectory in D-L space 507 during Stage 1 of the fault growth varies significantly, from sub-horizontal coherent508 like trajectories with limited displacement accrual (graph a), to steep and propagating- 
like trajectories with significant displacement accrual during Stage 1 (graph e). See text for full discussion.

\section{REFERENCES}

Ackermann, R. V., Schlische, R. W. \& Withjack, M. O. 2001. The geometric and statistical evolution of normal fault systems: an experimental study of the effects of mechanical layer thickness on scaling laws. Journal of Structural Geology 23(11), 1803-1819.

Acocella, V., Morvillo, P. \& Funiciello, R. 2005. What controls relay ramps and transfer faults within rift zones? Insights from analogue models. Journal of Structural Geology 27(3), 397-408.

Bastesen, E. \& Rotevatn, A. 2012. Evolution and structural style of relay zones in layered limestone-shale sequences: insights from the Hammam Faraun Fault Block, Suez rift, Egypt. Journal of the Geological Society 169(4), 477-488.

Baudon, C. \& Cartwright, J. A. 2008. 3D seismic characterisation of an array of blind normal faults in the Levant Basin, Eastern Mediterranean. Journal of Structural Geology 30(6), 746-760.

Bell, R. E., Duclaux, G., Nixon, C. W., Gawthorpe, R. L. \& McNeill, L. C. 2017. High-angle, not low-angle, normal faults dominate early rift extension in the Corinth Rift, central Greece. Geology.

Bellahsen, N. \& Daniel, J. M. 2005. Fault reactivation control on normal fault growth: an experimental study. Journal of Structural Geology 27(4), 769-780.

\section{Bergen, K. J. \& Shaw, J. H. 2010. Displacement profiles and displacement-length scaling relationships of thrust faults constrained by seismic-reflection data. Geological Society of America Bulletin 122(7-8), 1209-1219.}

Blækkan, I. 2016. Evolution of normal faults and fault-related damage: insights from physical experiments. Unpublished MSc thesis thesis, University of Bergen, Norway, http://hdl.handle.net/1956/12671.

Cartwright, J. A., Mansfield, C. S. \& Trudgill, B. D. 1996. Fault growth by segment linkage. In: Modern developments in structural interpretations (edited by Buchanan, P. C. \& Nieuwland, D. A.). Geological Society, London, Special Publications 99, 163-177.

Cartwright, J. A., Trudgill, B. D. \& Mansfield, C. S. 1995. Fault growth by segment linkage: an explanation for scatter in maximum displacement and trace length data from the Canyonlands Grabens of SE Utah. Journal of Structural Geology 17, 13191326. 
Childs, C., Holdsworth, R. E., Jackson, C. A. L., Manzocchi, T., Walsh, J. J. \& Yielding, G. 2017. Introduction to the geometry and growth of normal faults. Geological Society, London, Special Publications, SP439.23.

Childs, C., Watterson, J. \& Walsh, J. J. 1995. Fault overlap zones within developing normal fault systems. Journal of the Geological Society, London 152, 535-549.

Cladouhos, T. T. \& Marrett, R. 1996. Are fault growth and linkage models consistent with power-law distributions of fault lengths? Journal of Structural Geology 18(2-3), 281-293.

Clifton, A. E. \& Schlische, R. W. 2001. Nucleation, growth, and linkage of faults in oblique rift zones: Results from experimental clay models and implications for maximum fault size. Geology 29(5), 455-458.

Commins, D., Gupta, S. \& Cartwright, J. 2005. Deformed streams reveal growth and linkage of a normal fault array in the Canyonlands graben, Utah. Geology 33(8), 645648.

Cowie, P. 1998. A healing-reloading feedback control on the growth rate of seismogenic faults. Journal of Structural Geology 20(8), 1075-1087.

Cowie, P. A., Gupta, S. \& Dawers, N. H. 2000. Implications of fault array evolution for synrift depocentre development: insights from a numerical fault growth model. Basin Research 12(3-4), 241-261.

Cowie, P. A. \& Scholz, C. H. 1992a. Displacement-length scaling relationship for faults: data synthesis and discussion. Journal of Structural Geology 14(10), 11491156.

Cowie, P. A. \& Scholz, C. H. 1992b. Physical explanation for the displacement-length relationship of faults, using a post-yield fracture mechanics model. Journal of Structural Geology 14, 1133-1148.

Crider, J. G. \& Pollard, D. D. 1998. Fault linkage: Three-dimensional mechanical interaction between echelon normal faults. J. Geophys. Res. 103(B10), 24373-24391.

Davis, G. H., Reynolds, S. J. \& Kluth, C. F. 2011. Structural geology of rocks and regions. John Wiley \& Sons.

Dawers, N. H. \& Anders, M. H. 1995. Displacement-length scaling and fault linkage. Journal of Structural Geology 17(5), 607-614.

Dawers, N. H., Anders, M. H. \& Scholz, C. H. 1993. Growth of normal faults: Displacement-length scaling. Geology 21(12), 1107-1110.

Dawers, N. H. \& Underhill, J. R. 2000. The role of fault interaction and linkage in controlling synrift stratigraphic sequences: late Jurassic, Statfjord East Area, northern North Sea. AAPG Bulletin 84, 45-64. 
Finch, E. \& Gawthorpe, R. 2017. Growth and interaction of normal faults and fault network evolution in rifts: insights from three-dimensional discrete element modelling. Geological Society, London, Special Publications 439(1), 219-248.

\section{Fossen, H. 2016. Structural geology. Cambridge University Press.}

Fossen, H. \& Rotevatn, A. 2016. Fault linkage and relay structures in extensional settings-A review. Earth-Science Reviews 154, 14-28.

Gawthorpe, R., Leeder, M., Kranis, H., Skourtsos, E., Andrews, J., Henstra, G., Mack, G., Muravchik, M., Turner, J. \& Stamatakis, M. 2017. Tectono-sedimentary evolution of the Plio-Pleistocene Corinth rift, Greece. Basin Research.

Gawthorpe, R. L., Jackson, C. A. L., Young, M. J., Sharp, I. R., Moustafa, A. R. \& Leppard, C. W. 2003. Normal fault growth, displacement localisation and the evolution of normal fault populations: the Hammam Faraun fault block, Suez rift, Egypt. Journal of Structural Geology 25(6), 883-895.

Gawthorpe, R. L. \& Leeder, M. R. 2000. Tectono-sedimentary evolution of active extensional basins. Basin Research 12, 195-218.

Ge, Z., Nemec, W., Gawthorpe, R. L., Rotevatn, A. \& Hansen, E. W. M. 2017. Response of unconfined turbidity current to relay-ramp topography: insights from process-based numerical modelling. Basin Research, n/a-n/a.

Giba, M., Walsh, J. \& Nicol, A. 2012. Segmentation and growth of an obliquely reactivated normal fault. Journal of Structural Geology 39, 253-267.

Gudmundsson, A. \& Bäckström, K. 1991. Structure and development of the Sveinagja graben, northeast Iceland. Tectonophysics 200(1-3), 111-125.

Gupta, A. \& Scholz, C. H. 2000. A model of normal fault interaction based on observations and theory. Journal of Structural Geology 22(7), 865-879.

Gupta, S., Cowie, P. A., Dawers, N. H. \& Underhill, J. R. 1998. A mechanism to explain rift-basin subsidence and stratigraphic patterns through fault-array evolution. Geology 26(7), 595-598.

Hatem, A. E., Cooke, M. L. \& Toeneboehn, K. 2017. Strain localization and evolving kinematic efficiency of initiating strike-slip faults within wet kaolin experiments. Journal of Structural Geology 101, 96-108.

Hemelsdaël, R. \& Ford, M. 2016. Relay zone evolution: a history of repeated fault propagation and linkage, central Corinth rift, Greece. Basin Research 28(1), 34-56.

Henstra, G. A., Gawthorpe, R. L., Helland-Hansen, W., Ravnås, R. \& Rotevatn, A. 2017. Depositional systems in multiphase rifts: seismic case study from the Lofoten margin, Norway. Basin Research 29(4), 447-469.

Henstra, G. A., Rotevatn, A., Gawthorpe, R. L. \& Ravnås, R. 2015. Evolution of a major segmented normal fault during multiphase rifting: The origin of plan-view zigzag geometry. Journal of Structural Geology 74, 45-63. 
Horne, E. 2016. Kinematics and growth of supra-salt fault systems: A field and subsurface analysis, Salt Valley Salt Wall, Paradox Basin, Utah. Unpublished MSc thesis, Colorado School of Mines.

Huggins, P., Watterson, J., Walsh, J. \& Childs, C. 1995. Relay zone geometry and displacement transfer between normal faults recorded in coal-mine plans. Journal of Structural Geology 17(12), 1741-1755.

Hus, R., De Batist, M., Klerkx, J. \& Matton, C. 2006. Fault linkage in continental rifts: structure and evolution of a large relay ramp in Zavarotny; Lake Baikal (Russia). Journal of Structural Geology 28, 1338-1351.

Jackson, C. A.-L., Bell, R. E., Rotevatn, A. \& Tvedt, A. B. M. 2017. Techniques to determine the kinematics of synsedimentary normal faults and implications for fault growth models. Geological Society, London, Special Publications 439.

Jackson, C. A.-L., Gawthorpe, R. L. \& Sharp, I. R. 2002. Growth and linkage of the East Tanka fault zone, Suez rift: structural style and syn-rift stratigraphic response. Journal of the Geological Society 159(2), 175-187.

Jackson, C. A. L. \& Rotevatn, A. 2013. 3D seismic analysis of the structure and evolution of a salt-influenced normal fault zone: A test of competing fault growth models. Journal of Structural Geology 54, 215-234.

Kim, Y.-S. \& Sanderson, D. J. 2005. The relationship between displacement and length of faults: a review. Earth-Science Reviews 68(3-4), 317-334.

Krantz, R. W. 1988. The odd-axis model: orthorombic fault patterns and threedimensional strain fields. Unpublished PhD thesis, University of Arizona.

Mansfield, C. S. \& Cartwright, J. A. 2001. Fault growth by linkage: observations and implications from analogue models. Journal of Structural Geology 23, 745-763.

Marchal, D., Guiraud, M., Rives, T. \& van den Driessche, J. 1998. Space and time propagation processes of normal faults. Geological Society, London, Special Publications 147(1), 51-70.

Marrett, R. \& Allmendinger, R. W. 1990. Kinematic analysis of fault-slip data. Journal of structural geology 12(8), 973-986.

Marrett, R. \& Allmendinger, R. W. 1991. Estimates of strain due to brittle faulting: sampling of fault populations. Journal of Structural Geology 13(6), 735-738.

Marrett, R. \& Allmendinger, R. W. 1992. Amount of extension on" small" faults: An example from the Viking graben. Geology 20(1), 47-50.

McClay, K. \& White, M. 1995. Analogue modelling of orthogonal and oblique rifting. Marine and Petroleum Geology 12(2), 137-151.

McClay, K. R. 1990. Extensional fault systems in sedimentary basins: a review of analogue model studies. Marine and Petroleum Geology 7(3), 206-233. 
McGill, G. E., Schultz, R. A. \& Moore, J. M. 2000. Fault growth by segment linkage: an explanation for scatter in maximum displacement and trace length data from the Canyonlands grabens of SE Utah: Discussion. Journal of Structural Geology 22, 135140.

McLeod, A. E., Dawers, N. H. \& Underhill, J. R. 2000. The propagation and linkage of normal faults: insights from the Strathspey-Brent-Statfjord fault array, northern North Sea. Basin Research 12, 263-284.

Meyer, V., Nicol, A., Childs, C., Walsh, J. \& Watterson, J. 2002. Progressive localisation of strain during the evolution of a normal fault population. Journal of Structural Geology 24(8), 1215-1231.

Morewood, N. C. \& Roberts, G. P. 1999. Lateral propagation of the surface trace of the South Alkyonides normal fault segment, central Greece: its impact on models of fault growth and displacement-length relationships. Journal of Structural Geology 21(6), 635-652.

Morley, C., Nelson, R., Patton, T. \& Munn, S. 1990. Transfer zones in the East African rift system and their relevance to hydrocarbon exploration in rifts (1). $A A P G$ Bulletin 74(8), 1234-1253.

Nicol, A., Childs, C., Walsh, J. J., Manzocchi, T. \& Schöpfer, M. P. J. 2016. Interactions and growth of faults in an outcrop-scale system. Geological Society, London, Special Publications 439.

Nicol, A., Walsh, J., Berryman, K. \& Nodder, S. 2005. Growth of a normal fault by the accumulation of slip over millions of years. Journal of Structural Geology 27(2), 327-342.

Nicol, A., Walsh, J. J., Villamor, P., Seebeck, H. \& Berryman, K. R. 2010. Normal fault interactions, paleoearthquakes and growth in an active rift. Journal of Structural Geology 32(8), 1101-1113.

Nixon, C. W., McNeill, L. C., Bull, J. M., Bell, R. E., Gawthorpe, R. L., Henstock, T. J., Christodoulou, D., Ford, M., Taylor, B. \& Sakellariou, D. 2016. Rapid spatiotemporal variations in rift structure during development of the Corinth Rift, central Greece. Tectonics 35(5), 1225-1248.

Peacock, D., Nixon, C., Rotevatn, A., Sanderson, D. \& Zuluaga, L. 2017. Interacting faults. Journal of Structural Geology 97, 1-22.

Peacock, D. \& Sanderson, D. 1996. Effects of propagation rate on displacement variations along faults. Journal of Structural Geology 18(2-3), 311-320.

Peacock, D. C. P. \& Sanderson, D. J. 1991. Displacements, segment linkage and relay ramps in normal fault zones. Journal of Structural Geology 13, 721-733.

Peacock, D. C. P. \& Sanderson, D. J. 1994. Geometry and development of relay ramps in normal fault systems. AAPG Bulletin 78, 147-165. 
Rotevatn, A. \& Fossen, H. 2012. Soft faults with hard tips: magnitude-order displacement gradient variations controlled by strain softening versus hardening; implications for fault scaling. Journal of the Geological Society 169(2), 123-126.

Rotevatn, A., Kristensen, T. B., Ksienzyk, A. K., Wemmer, K., Henstra, G. A., Midtkandal, I., Grundvåg, S. A. \& Andresen, A. 2018. Structural Inheritance and Rapid Rift-Length Establishment in a Multiphase Rift: The East Greenland Rift System and its Caledonian Orogenic Ancestry. Tectonics 37.

Rykkelid, E. \& Fossen, H. 2002. Layer rotation around vertical fault overlap zones: observations from seismic data, field examples and physical experiment. Marine and Petroleum Geology 19, 181-192.

Schlagenhauf, A., Manighetti, I., Malavieille, J. \& Dominguez, S. 2008. Incremental growth of normal faults: Insights from a laser-equipped analog experiment. Earth and Planetary Science Letters 273(3), 299-311.

Schlische, R. W., Young, S. S., Ackermann, R. V. \& Gupta, A. 1996. Geometry and scaling relations of a population of very small rift-related normal faults. Geology 24(8), 683-686.

Schultz, R. A. \& Fossen, H. 2002. Displacement-length scaling in three dimensions: the importance of aspect ratio and application to deformation bands. Journal of Structural Geology 24, 1389-1411.

Schultz, R. A., Soliva, R., Fossen, H., Okubo, C. H. \& Reeves, D. M. 2008. Dependence of displacement-length scaling relations for fractures and deformation bands on the volumetric changes across them. Journal of Structural Geology 30(11), 1405-1411.

Soliva, R. \& Benedicto, A. 2004. A linkage criterion for segmented normal faults. Journal of Structural Geology 26(12), 2251-2267.

Soliva, R., Benedicto, A., Schultz, R. A., Maerten, L. \& Micarelli, L. 2008. Displacement and interaction of normal fault segments branched at depth: Implications for fault growth and potential earthquake rupture size. Journal of Structural Geology 30(10), 1288-1299.

Taylor, S. K., Bull, J. M., Lamarche, G. \& Barnes, P. M. 2004. Normal fault growth and linkage in the Whakatane Graben, New Zealand, during the last 1.3 Myr. Journal of Geophysical Research: Solid Earth 109(B2).

Torabi, A. \& Berg, S. S. 2011. Scaling of fault attributes: A review. Marine and Petroleum Geology 28(8), 1444-1460.

Trudgill, B. D. \& Cartwright, J. A. 1994. Relay ramp forms and normal fault linkages, Canyonlands National Park, Utah. GSA Bulletin 106, 1143-1157.

Tvedt, A. B. M. 2016. The geometry and evolution of supra-salt normal fault arrays. Unpublished $\mathrm{PhD}$ thesis thesis, University of Bergen, Norway. 
Tvedt, A. B. M., Rotevatn, A. \& Jackson, C. A. L. 2016. Supra-salt normal fault growth during the rise and fall of a diapir: Perspectives from 3D seismic reflection data, Norwegian North Sea. Journal of Structural Geology 91, 1-26.

Tvedt, A. B. M., Rotevatn, A., Jackson, C. A. L., Fossen, H. \& Gawthorpe, R. L. 2013. Growth of normal faults in multilayer sequences: A 3D seismic case study from the Egersund Basin, Norwegian North Sea. Journal of Structural Geology 55, 1-20.

Walsh, J. J., Bailey, W. R., Childs, C., Nicol, A. \& Bonson, C. G. 2003. Formation of segmented normal faults: a 3-D perspective. Journal of Structural Geology 25(8), 1251-1262.

Walsh, J. J. \& Watterson, J. 1988. Analysis of the relationship between displacements and dimensions of faults. Journal of Structural Geology 10(3), 239-247.

Watterson, J. 1986. Fault dimensions, displacements and growth. Pure and Applied Geophysics 124(1-2), 365-373.

Wells, D. L. \& Coppersmith, K. J. 1994. New empirical relationships among magnitude, rupture length, rupture width, rupture area, and surface displacement. Bulletin of the seismological Society of America 84(4), 974-1002.

Wojtal, S. F. 1996. Changes in fault displacement populations correlated to linkage between faults. Journal of Structural Geology 18(2-3), 265-279. 
Fig. 1

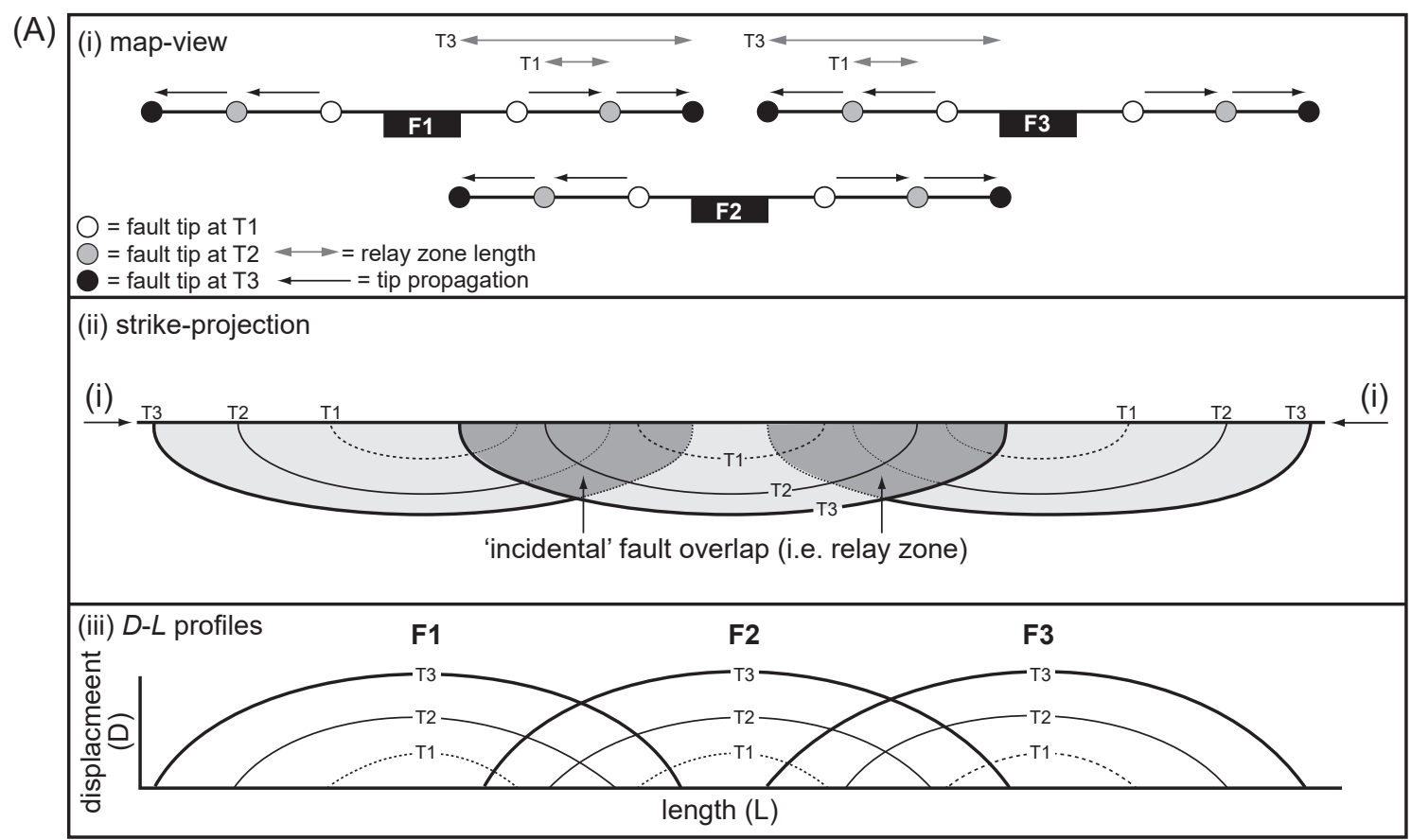

(B)

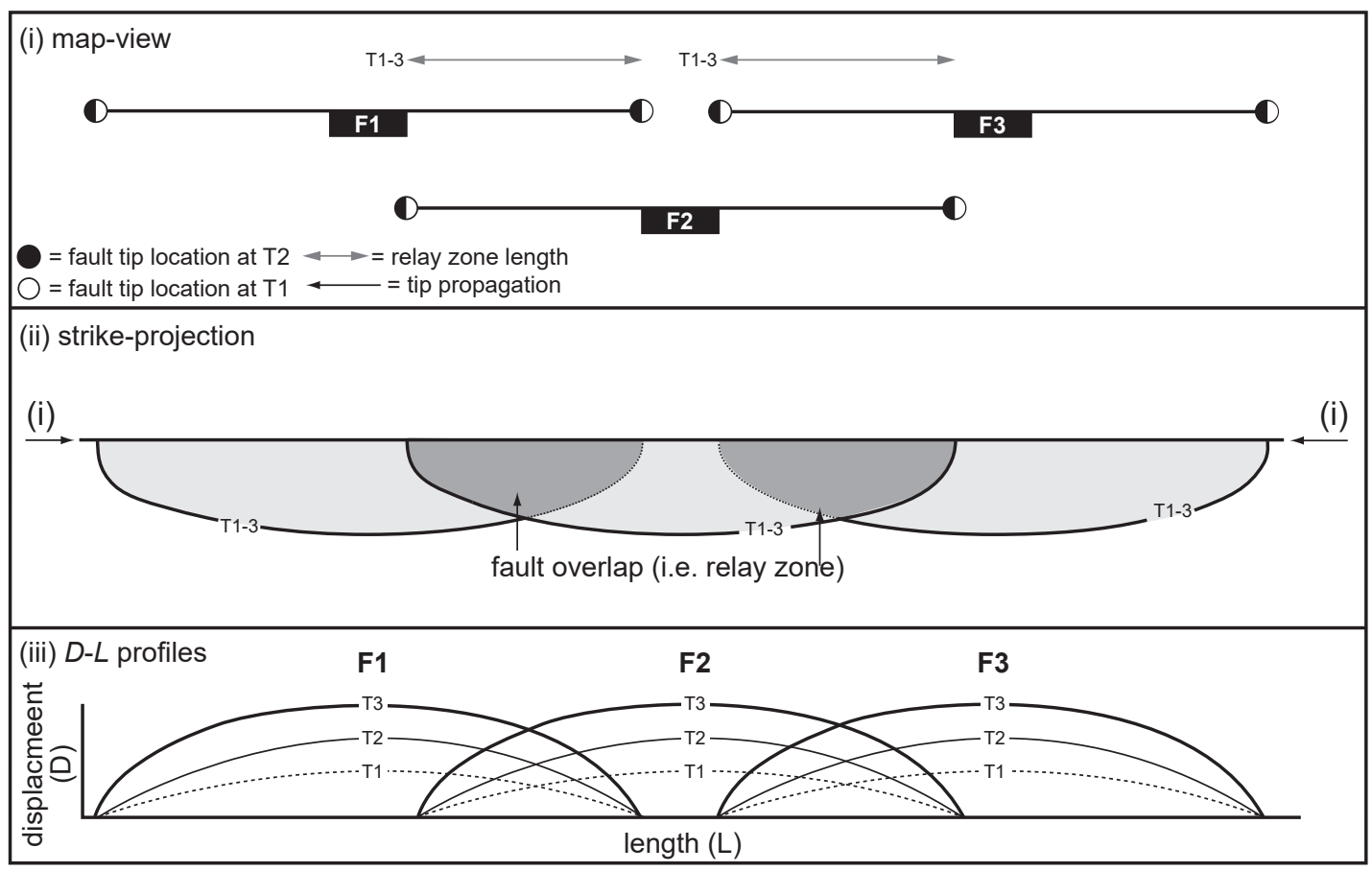

(C)

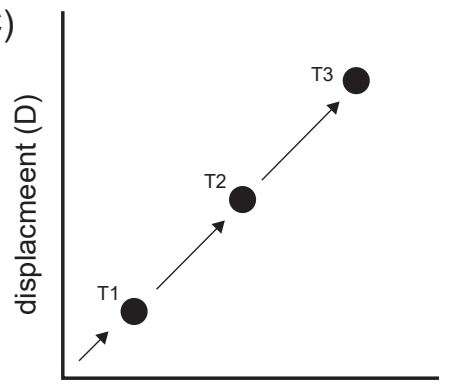

length (L)
(D)

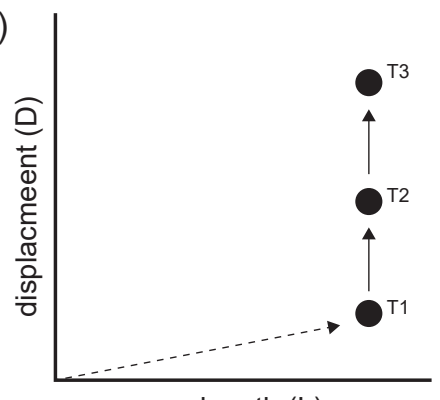

length (L) 

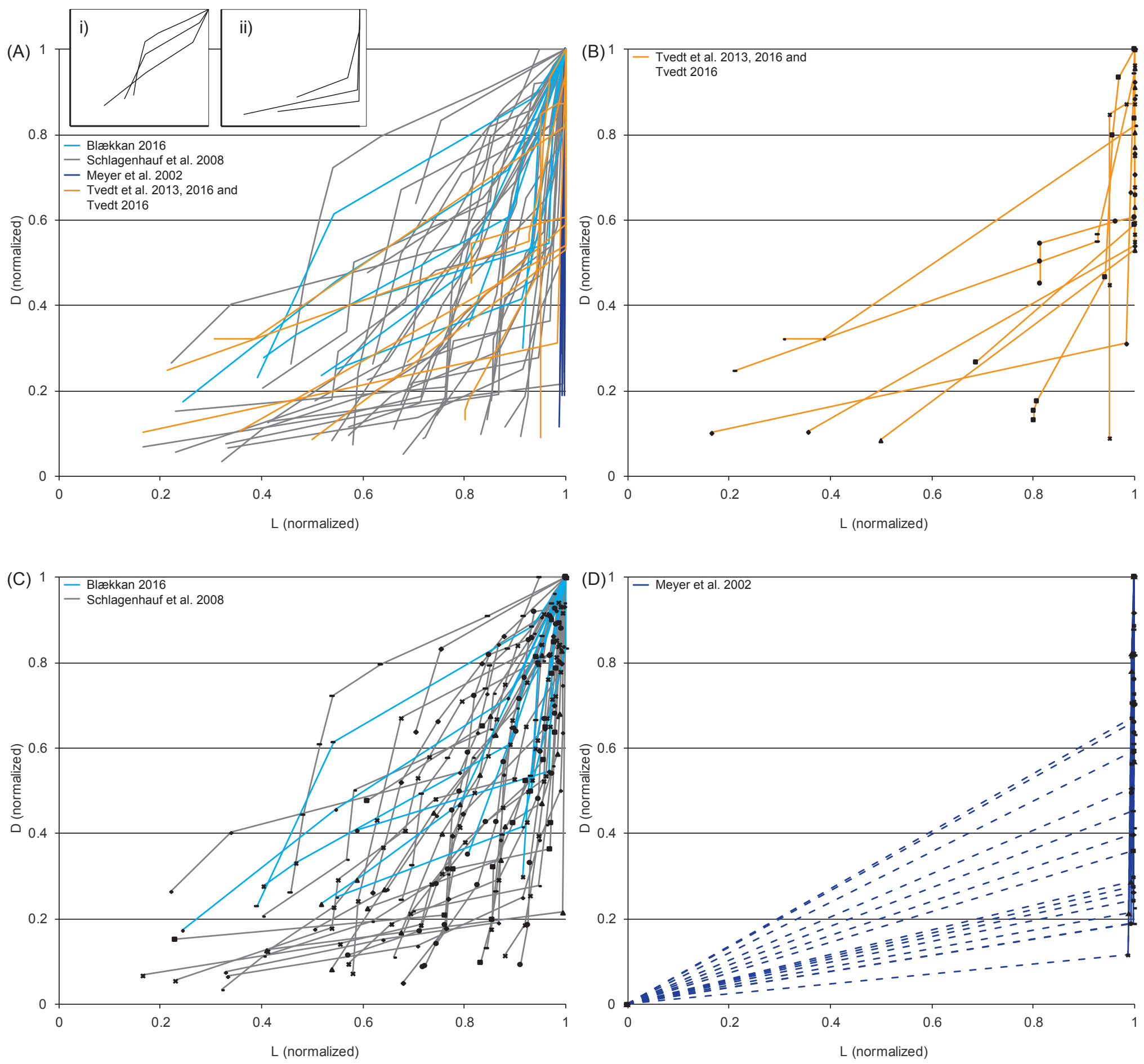


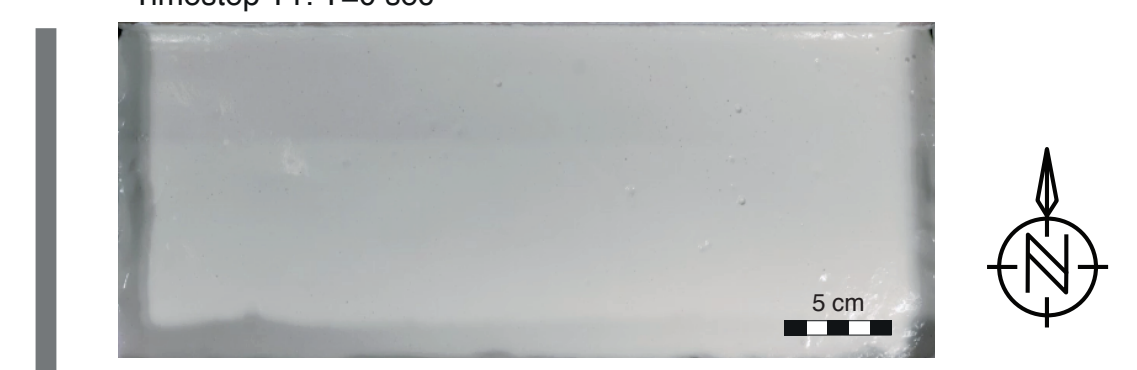

Timestep T2: $T=5.0 \mathrm{sec}$
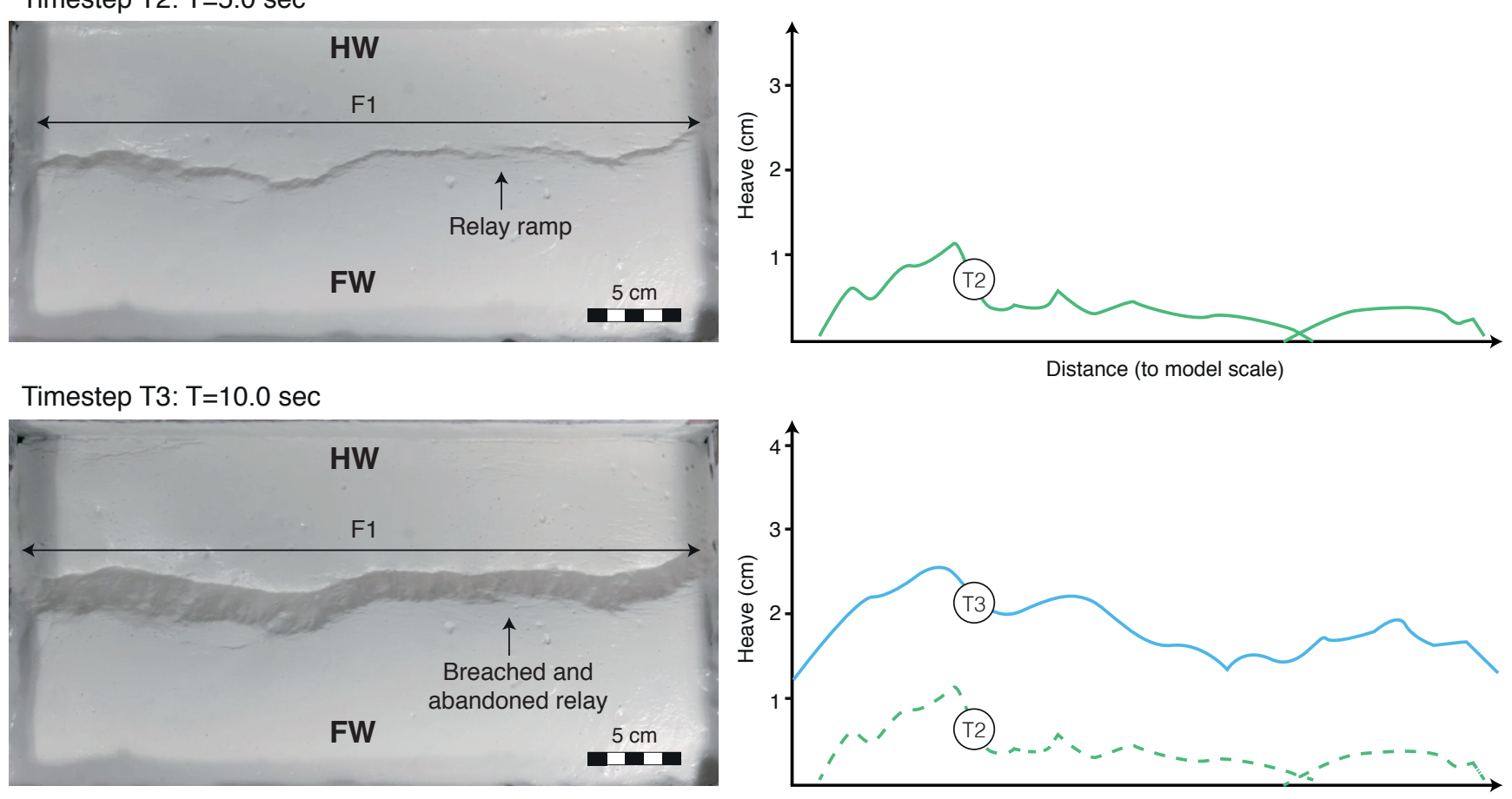

Timestep T4: $\mathrm{T}=15.0 \mathrm{sec}$
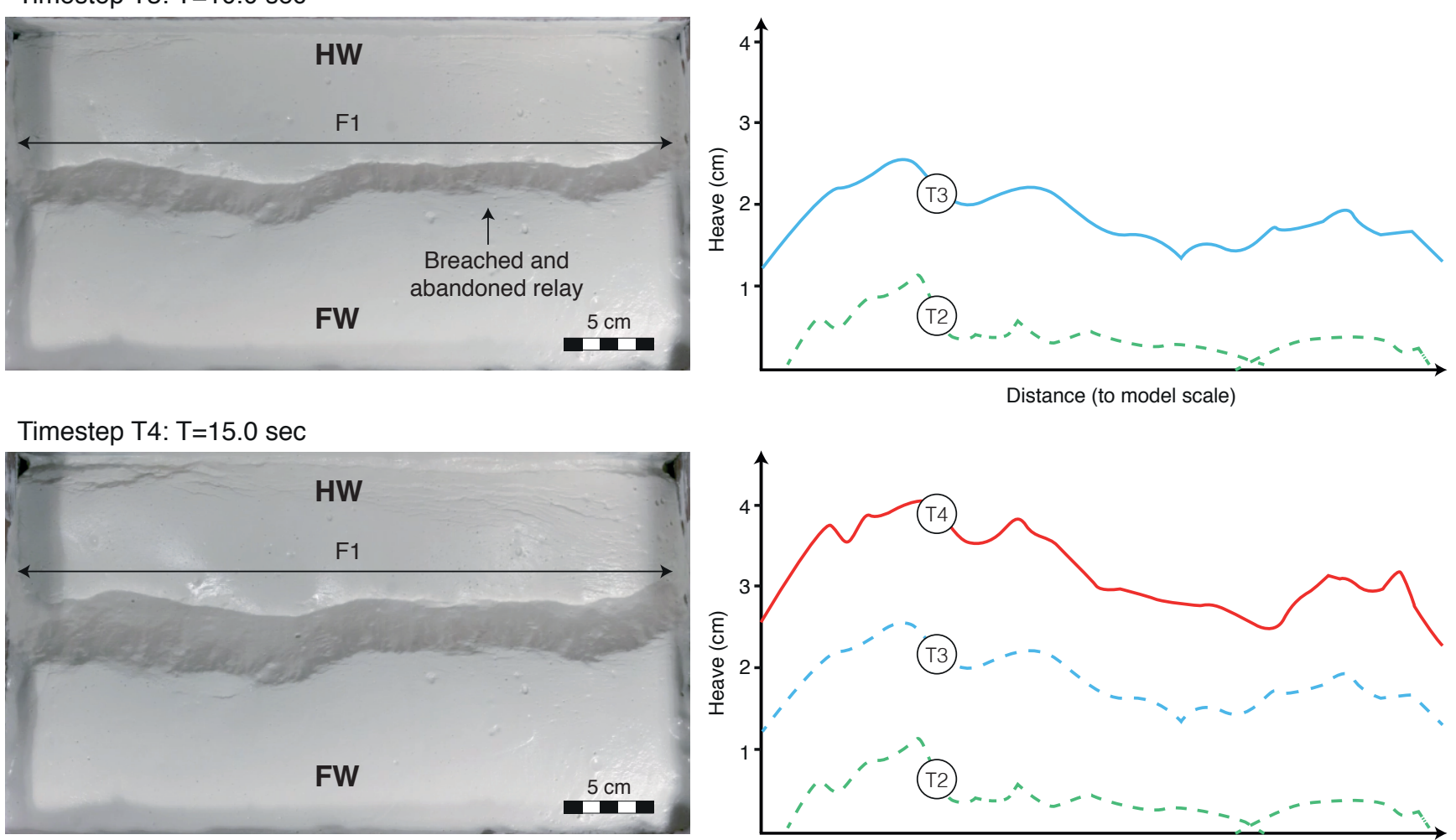

Distance (to model scale)

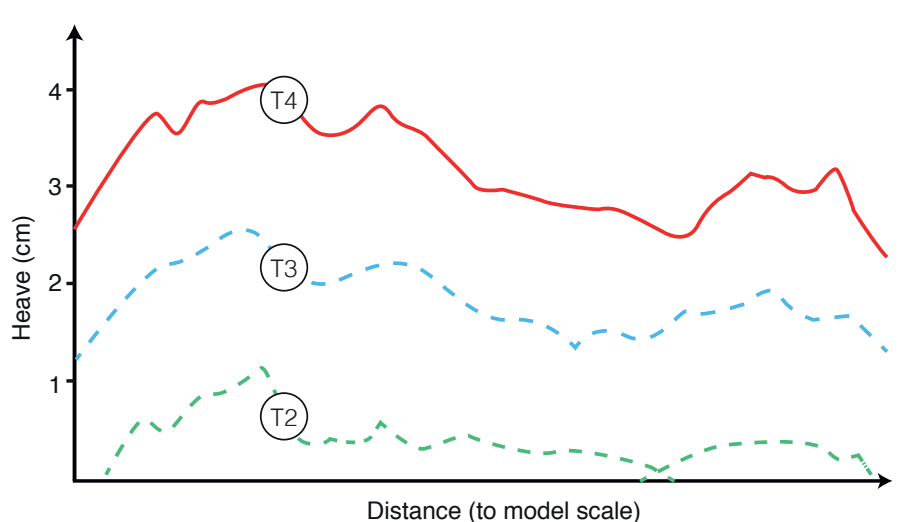


Timestep T1a: $\mathrm{T}=5.5 \mathrm{sec}$
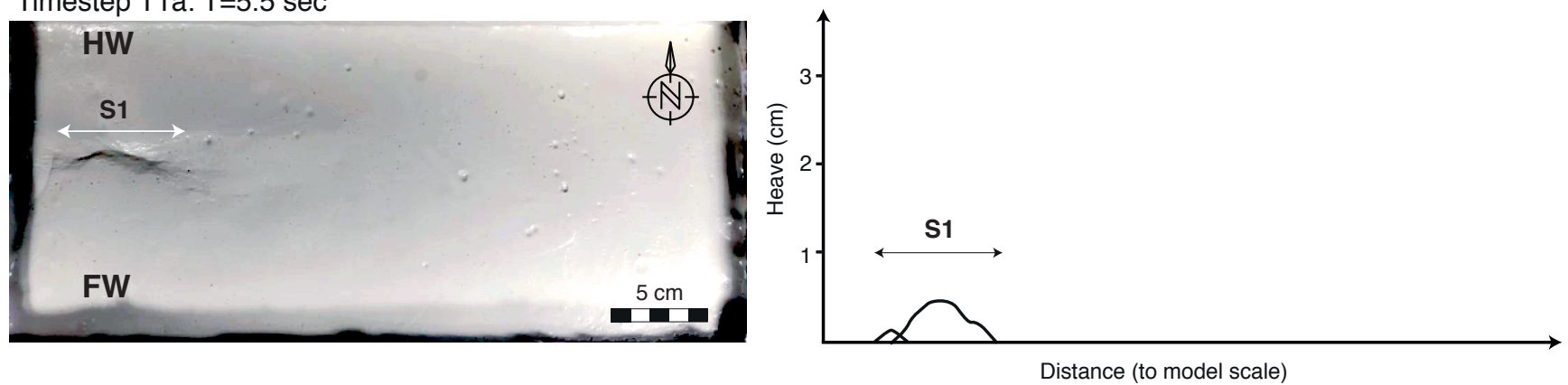

Distance (to model scale)

Timestep T1b: T=6.0 sec
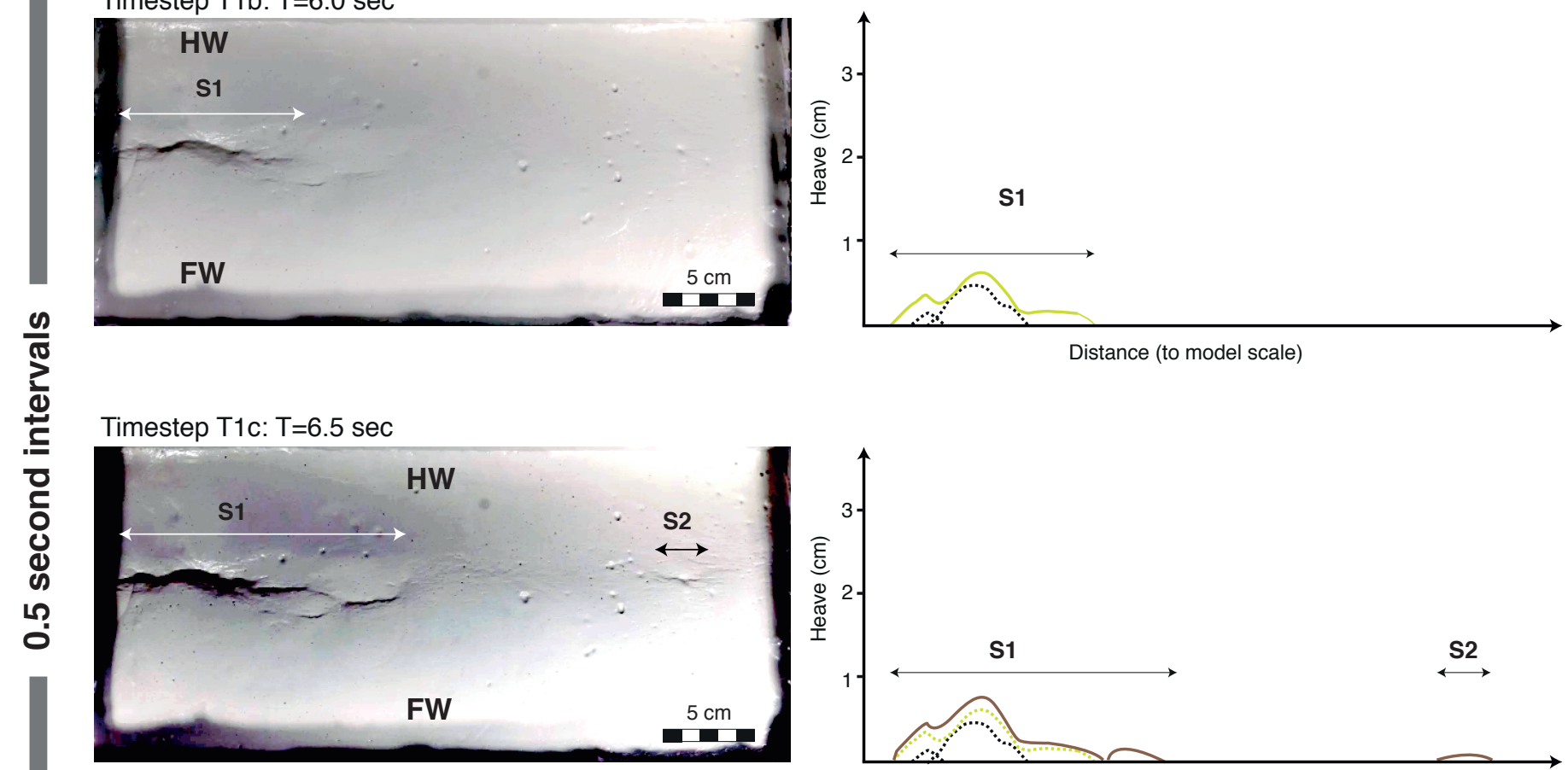

Distance (to model scale)

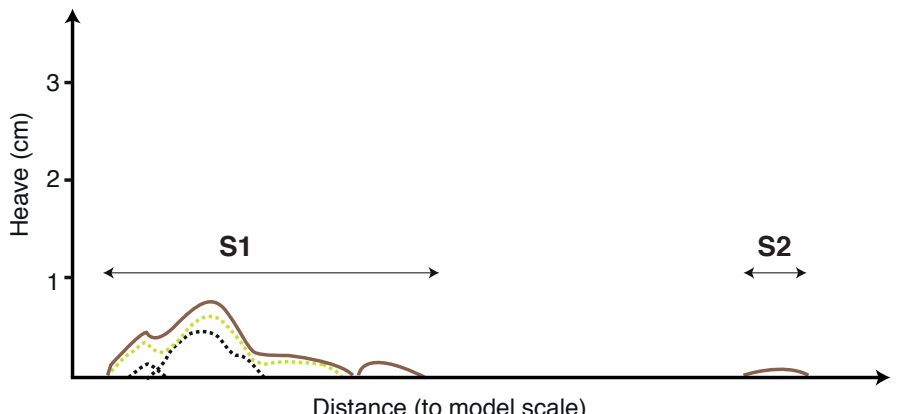

Timestep T1d: T=7.0 sec
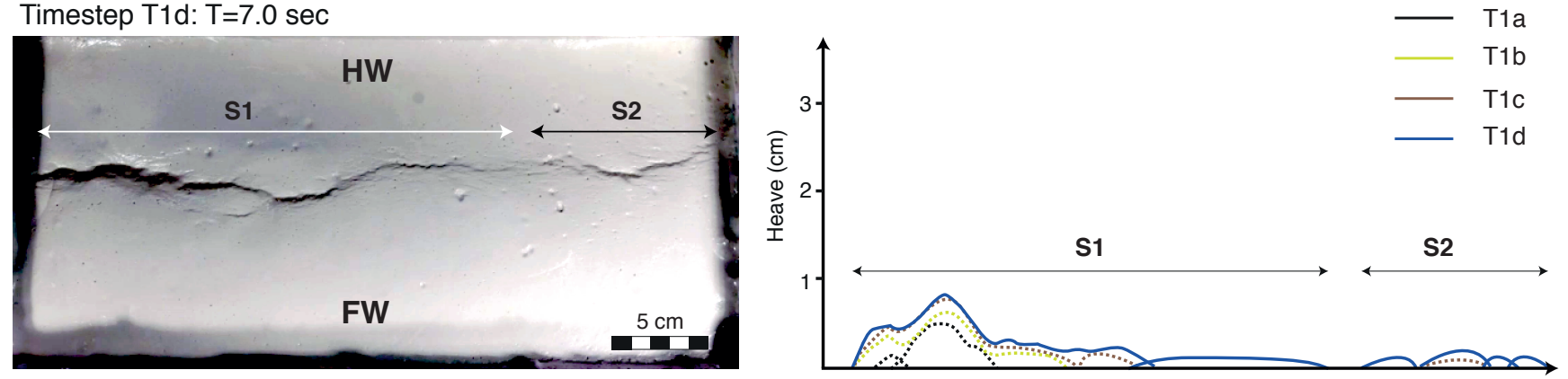

Distance (to model scale) 


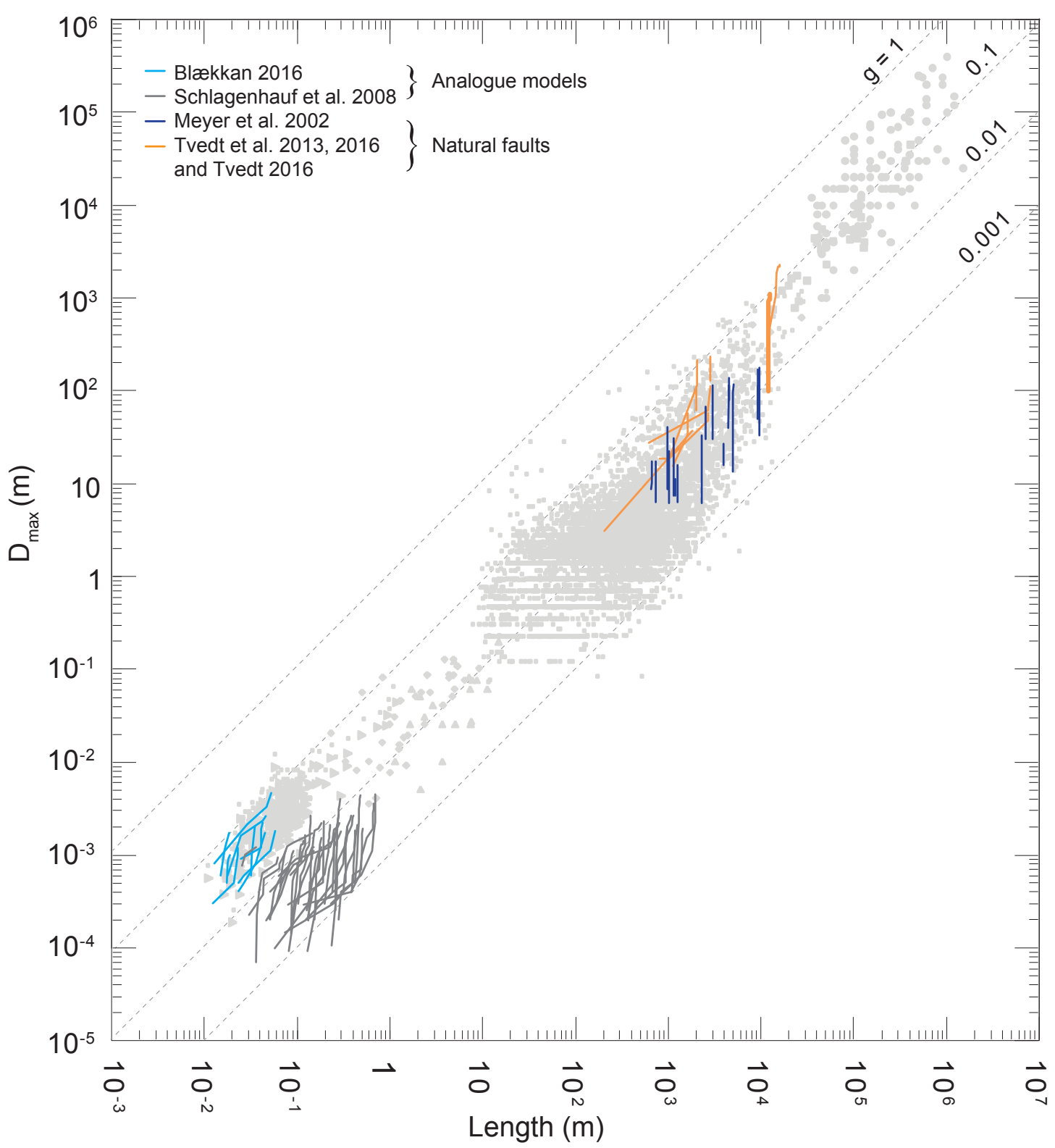




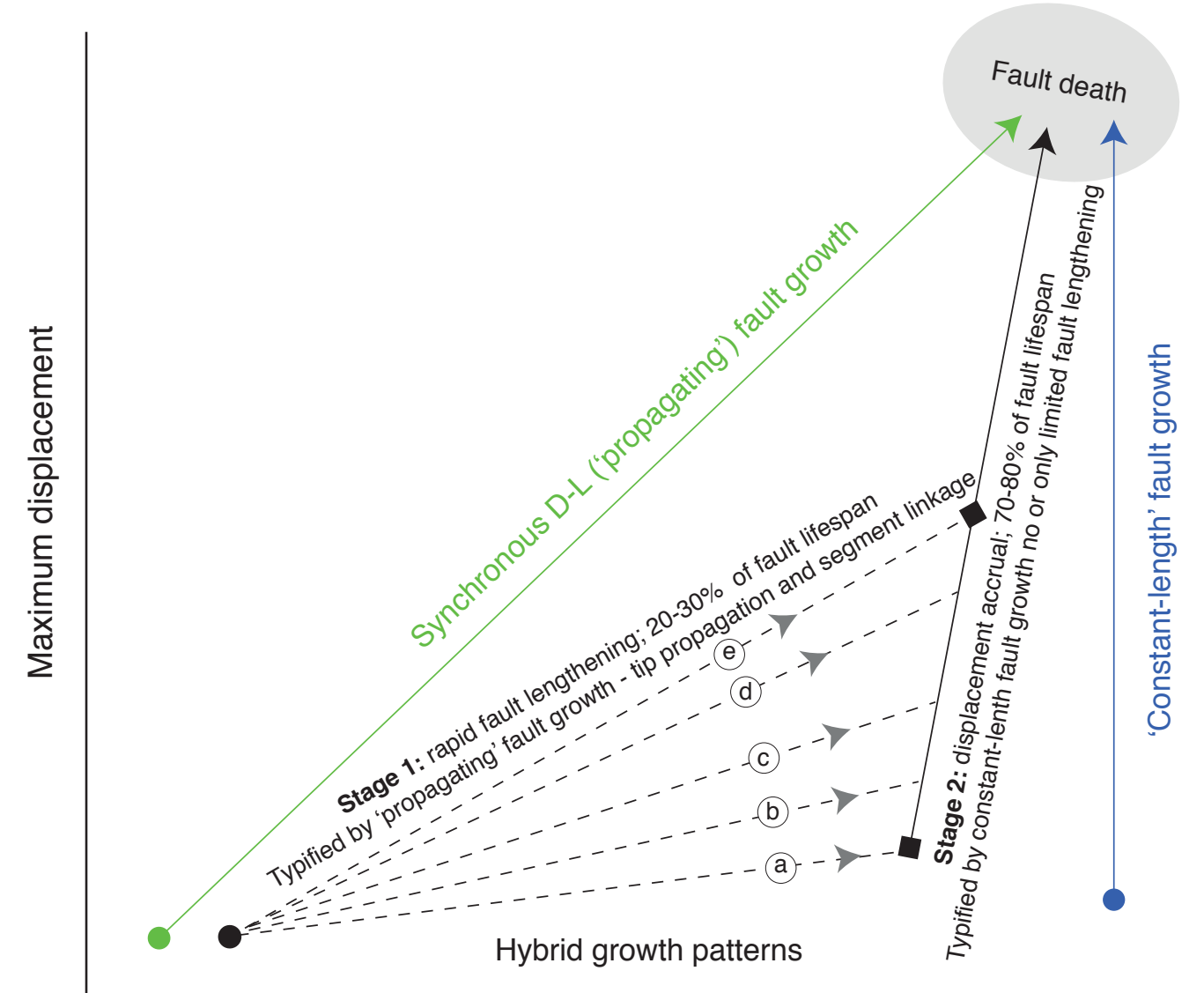

Length 